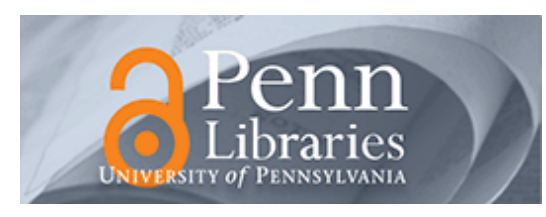

University of Pennsylvania ScholarlyCommons

$10-2011$

\title{
How to Overcome Strawson's Point: Defending a Value-Oriented Foundation for Contractualism
}

\author{
Doug Paletta \\ University of Pennsylvania, paletta@sas.upenn.edu
}

Follow this and additional works at: https://repository.upenn.edu/miscellaneous_papers

Part of the Ethics and Political Philosophy Commons

Paletta, Doug, "How to Overcome Strawson's Point: Defending a Value-Oriented Foundation for Contractualism" (2011).

Miscellaneous Papers. 15.

https://repository.upenn.edu/miscellaneous_papers/15

This is a post-peer-review, pre-copyedit version of an article published in Ethical Theory and Moral Practice. The final authenticated version is available online at: Paletta, D. Ethic Theory Moral Prac (2013) 16:9. https://doi.org/10.1007/s10677-011-9328-1

This paper is posted at ScholarlyCommons. https://repository.upenn.edu/miscellaneous_papers/15

For more information, please contact repository@pobox.upenn.edu. 


\title{
How to Overcome Strawson's Point: Defending a Value-Oriented Foundation for Contractualism
}

\begin{abstract}
In The Second Person Standpoint, Darwall charges that all value-oriented foundations for ethics make a category mistake. Calling it Strawson's point, he argues these foundations explain moral authority, which concerns whether someone has standing to hold another accountable, in terms of a value, which essentially concerns what makes the world go best. However, whether it would be good for me to blame you simply asks a different question than whether I have standing to blame you. I defend a value-oriented foundation for contractualism by identifying one way to overcome Strawson's point. At bottom, Darwall's objection relies on the assumption that all values are world regarding. I argue that another class of values exists: second-personal values. Grounding morality in one of these values does not make the category mistake at the heart of Strawson's point. In particular, I argue that grounding morality on one second personal value, the ideal of acting justifiably towards others, better captures traditional contractualist ideals than Darwall's formal foundation.
\end{abstract}

\section{Keywords}

Contractualism, Strawson's Point, Darwall

\section{Disciplines}

Ethics and Political Philosophy

\section{Comments}

This is a post-peer-review, pre-copyedit version of an article published in Ethical Theory and Moral Practice. The final authenticated version is available online at: Paletta, D. Ethic Theory Moral Prac (2013) 16:9. https://doi.org/10.1007/s10677-011-9328-1 


\section{How to overcome Strawson's point: Defending a value-oriented foundation for} contractualism $^{1}$

In The Second-Person Standpoint, Stephen Darwall proposes a new foundation for contractualism. Rather than begin with an ideal or value, like fairness, Darwall attempts to ground contractualism in the way we practically engage others. He focuses on the requirements, or "felicity conditions," for the family of interactions we have with one another, such as blaming, demanding and holding accountable. Interacting with others in these ways requires approaching them second personally, as an agent with standing recognizing and engaging other agents with standing. The demands that arise from engaging others second personally cannot be captured when engaging others first personally, from my private view, or third personally, from the view of the world. Successfully grounding contractualism in the requirements for second-personal interaction provides a firmer and more general foundation than approaches that depend on our (possibly contingent) values. Despite its promise, Darwall's novel approach sacrifices important elements of the traditional contractualist ideals of substantive equality and the idea that moral principles should be justifiable to each. A value-oriented foundation that builds on the value of acting justifiably towards others better secures these ideals.

Darwall levels a fundamental challenge against any attempt to ground contractualism in a substantive value. Calling it Strawson's point, Darwall states, "considerations of desirability [or being valuable] ... are simply reasons of the wrong kind to ground (second-personal) reasons of moral obligation and right" (Darwall 2006, p. 317). That it would be good for you to have a certain authority over me cannot establish that you in fact have that authority. More generally, determining whether or not some relationship is good just asks a different question than whether or not we actually stand in the relationship. Strawson's point, if correct, forces contractualists to adopt a formal foundation. Appealing to any substantive ideal or value to ground contractualism prima facie presents reasons of the wrong kind to ground an account of morality. Doing so would establish that moral relationships are valuable, not that we must stand in them.

My defense of a value-oriented foundation for contractualism proceeds in two steps. After laying out Strawson's point in more detail (I), I show how one class of values overcomes Strawson's point: namely, second-personal values (II). To arrive at which values are second personal, I apply to the realm of values Darwall's standard for distinguishing second from thirdpersonal demands. Second-personal values are values that include an irreducibly second-personal element. Grounding contractualism on one of these values satisfies Strawson's point. After establishing the possibility of providing a value-oriented foundation for contractualism, I defend a particular value, the ideal of acting justifiably towards others, as a better foundation for contractualism than Darwall's formal foundation (III). Both foundations broadly overlap. Since each grounds a version of contractualism, both foundations ground an account of morality where

\footnotetext{
${ }^{1}$ This is a post-peer-review, pre-copyedit version of an article published in Ethical Theory and Moral Practice. The final authenticated version is available online at: https://doi.org/10.1007/s10677-011-9328-1
} 
moral principles should be justifiable to each, should express equality and are grounded in the second-personal perspective. However, the substantive and formal foundations come apart in how they characterize each of these ideals. A substantive foundation based on the ideal of justifiability to others better secures traditional interpretations of these ideals and the content of the contractualist principle. Taken together, I show that Strawson's point does not preclude a substantive foundation for contractualism and suggest several reasons contractualists ought to prefer a value-oriented foundation.

\section{Strawson's point}

Darwall presents his strongest objection against value-oriented foundations for our moral relationships in Strawson's point. The point builds on P.F. Strawson's insight about our attitudes towards other agents (Strawson 1962, p. 25). Darwall puts the point this way:

When we seek to hold people accountable, what matters is not whether doing so is desirable, either in a particular case or in general, but whether the person's conduct is culpable and we have the authority to bring him to account (Darwall 2006, p. 15).

Strawson identifies two attitudes we can take towards others: a participant reactive attitude and an objective attitude. The two attitudes differ precisely in whether we treat someone as an agent, to be engaged, or as something, to be managed. We treat children objectively. We respond to and manage their behavior in light on what is good for them. We do not blame a child, we correct his behavior. From the objective perspective, we cannot hold someone morally responsible for her actions. This basic difference in how we treat humans begins to capture Darwall's distinction between the second and third-personal perspective. When we engage the world third personally we treat people clinically, as objects in the world. When we engage second personally we recognize and engage others as agents. Strawson's insight highlights the kind of considerations that certain moral judgments, including reactive attitudes, presuppose. Considerations about what make the world go best are irrelevant to judgments of culpability, and the foundation of a morality theory should account for this.

Darwall builds on Strawson's point to level three challenges against moral theories based on values. First, Darwall charges that considerations of value are unable to secure the priority of morality. He asks how, "from the fact it would be desirable for us to treat considerations of right as having priority over other values ... can [it] possibly follow that such considerations actually have this priority?" (Darwall 2006, p. 317). In part, this problem arises because considerations about what make the world go best can seemingly be trumped by considerations of right. For instance, even if it would be desirable in a particular case to violate someone's rights to expedite the legal discovery process, due process should be upheld. Second, the central problem facing value-based accounts is "that it is hard to see how its being desirable that we relate to one another on terms of mutual accountability can possibly ground the distinctively second-personal 
claim that we are mutually accountable" (Darwall 2006, p. 317). Related to the first point, the second challenge identifies a category mistake - using ( $3^{\text {rd }}$ personal) world-regarding considerations to account for the significance of ( $2^{\text {nd }}$ personal) recognition-based authority relations. These challenges also point to a third potential problem. If successful, using desirability or value to explain the significance of second-personal relations may only afford the relationships instrumental or derivative significance. Moral relationships only matter insofar as they promote some further world-regarding value. So, Strawson's point raises three problems for value-oriented foundations for contractualism: (1) considerations of value cannot secure the priority of right, (2) even if they could, the concept of value is world regarding and thus cannot ground second-personal demands and (3) grounding second-personal demands on third-personal considerations affords them instrumental or derivative significance.

Darwall considers the views of Mill and Scanlon to highlight the category mistake in providing a value-oriented foundation for our moral relationships. Mill argues that the ultimate sanction of utilitarianism lies in its desirability. Why utilitarianism? It makes the world go better. Darwall argues Scanlon makes a similar move to establish the authority of morality. Scanlon's early view identified the "desire to act in ways that can be justified to others" (Darwall 2006, p. 316; Scanlon 1982, p. 116) as the basis for why someone should not act wrongly. On this reading, Mill and Scanlon both directly fall to Strawson's point. As Darwall sees it, we desire standing in a particular relation to others "either impartially or from our own point of view" (Darwall 2006, p. 317). Grounding moral relationships on their impartial desirability provides a third-personal foundation for second-personal relationship or claims. Alternatively, if moral considerations give me reasons to act because I desire them or find them appealing, the foundation is first personal. So, desire or desirability will provide either a third or first-personal ground for moral responsibility, which provides a basis of the wrong kind for second-personal relationships.

While Darwall phrases Strawson's point in terms of desirability, the same critique can be made in terms of value. One of the central developments in Scanlon's account of moral motivation from "Contractualism and Utilitarianism" to What we Owe to Each Other is his rejection of desire-based models for action. Instead, he claims that a desire only provides a reason to act when we judge that further considerations count in favor of pursuing the object of that desire (Scanlon 1998, pp. 37-41). Samuel Freeman notes the nascent version of this view in his commentary on "Contractualism and Utilitarianism." As he puts the point, "this desire [for rational agreement] presumes an account of the subject matter of morality as part of its content" (Freeman 1991, p. 292). For this desire to provide a reason to act, considerations must count in favor of pursuing this object. In keeping with the rejection of the desire based model, these considerations show that acting on the desire for rational agreement is valuable. Acting on the desire is good. However, this shift from the desirability of acting morally to the value of acting morally still faces Strawson's point. In the same way that the desirability of blaming someone cannot trigger the reactive attitude, prima facie the value of blaming still provides the wrong 
kind of reason to blame them. What matters is whether the person did something wrong and we have standing to blame, not the goodness or value of blaming.

Looking more specifically at the bindingness of obligations demonstrates why these value-oriented foundations fail. On a desirability-based approach, how should we understand obligations to friends or obligations to keep promises? Meeting those obligations promotes utility or is part of what it means to be able to justify actions to others. Promoting utility or being able to justify actions to others matters because of its desirability or value. This way of explaining the significance of obligations and why we should keep them fails to satisfy Strawson's point. Nothing about our obligations affords them a special place in practical reasoning. Rather, keeping promises is one action among others that secures desirable outcomes and we should only prioritize keeping promises insofar as doing so happens to promote more desirable outcomes. This problem arises because the act of keeping promises is not different in kind than any other type of action that secures desirable outcomes. Beginning with the notion of desirability, all actions are viewed third personally, and the moral significance of actions, such as keeping promises, comes from their relationship to securing these good outcomes.

So, using Strawson's point Darwall levels three distinct objections against value-oriented foundations for morality. First, value-oriented foundations cannot explain the priority or special significance we normally associate with moral demands. Such a foundation can only show that acting morally is one good thing among others. Second, if values are world regarding, they cannot ground distinctly second-personal authoritative forms of address. World-regarding values literally provide the wrong kind of basis for second-personal demands. Finally, value-oriented foundations only afford instrumental or derivative significance to our moral relations. Darwall concludes “the lesson of Strawson's point is that an adequate theory of moral responsibility must invoke standards that are internal to the second-person standpoint" (Darwall 2006, pp. 146-147). If Strawson's point stands, contractualists must adopt a formal foundation, like Darwall's secondpersonal perspective.

\section{Darwall's Solution: A Formal Foundation}

Darwall approaches moral theory by analyzing what second-personal address involves. The second-personal perspective is a practical perspective. Reasons from this perspective apply in virtue of mutually acceptable norms of authority. For instance, by freely joining the military I accept that a sergeant's orders give me a reason to do something because she's the sergeant. Other reasons to abide by the order, such as prudential reasons, cannot capture the reason I have in virtue of my relationship to the sergeant. To make sense of this perspective, Darwall introduces a circle of irreducibly second-personal ideas including second-personal authority, dignity, obligation and accountability. Darwall presents another central example to help clarify these ideas (Darwall 2006, p. 12). Imagine a case where Stomper is standing on Irritated's foot. Irritated can give Stomper at least two kinds of reasons to move his foot. One set of reasons is third personal, world regarding, and does not refer back to Irritated. Standing on feet causes pain. If Stomper thinks causing pain in the world is bad, that fact will give him a reason to move his 
foot. Irritated, however, can give a second kind of reason; she can demand Stomper get off because it's her foot. This is a second-personal reason. Darwall states its "validity depends on presupposed authority and accountability relations between persons" (Darwall 2006, p. 8). In this case, Irritated's demand only counts as a reason for Stomper to move his foot if Irritated has the authority to make the demand. While the relationship between second-personal concepts and how they provide a foundation for contractualism can only be sketched here, briefly laying out how the concepts relate to one another illustrates Darwall's formal approach to the foundation of contractualism.

Several concepts or claims must be in play for Irritated's demand to provide a reason for Stomper to remove his foot. Stomper must recognize that Irritated has the authority to make her demand. If a private demands a sergeant do push-ups, the demand misfires precisely because the private does not stand in the appropriate authority relation to the sergeant. By recognizing Irritated's authority, Stomper recognizes that he is obligated to abide by her demand and that he can be held accountable and blamed for failing to abide by it. In accepting any of these elements - Irritated's authority, his obligation, or the fact that he is blameworthy - Stomper affirms the authority relation itself. That is, Stomper affirms that Irritated's demand is valid because of his relationship with her. Conversely, Irritated presupposes the authority to issue the demand when she makes it. Each of these concepts makes sense only when all the other concepts are invoked (Darwall 2006, pp. 269-276). By issuing and accepting the demand, Stomper and Irritated affirm an authority relationship second personally.

Important for later, Darwall argues the standards we invoke with these person-to-person demands are the standards of a moral community. Accountability and demands are "regarded and addressed ... [by everyone] within the second-personal relationships we stand in as members of the moral community" (Darwall 2006, p. 69). Addressing a demand or holding someone (including yourself) accountable assumes the addressee "can take a second-personal perspective on themselves and act on reasons they accept from that point of view" (Darwall 2006, p. 75). The moral community that undergirds Darwall's irreducible circle is not an actual community, but a point of view that represents second-personal relationships in a community where members can reasonably make demands and hold one another accountable.

Darwall's irreducible circle leads him to affirm a version of contractualism: "an act is wrong if the act would be disallowed by a principle no one could reasonably reject our holding one another accountable for complying with" (Darwall 2006, p. 301). Respecting each other's standing as someone who can issue demands and be held accountable requires that we affirm and act in accordance with authority relations acceptable from the second-personal perspective. He contends, "it is the right's connection to accountability, indeed, that makes a "no-reasonablerejection' test appropriate in the first place. It is because a moral obligation presents a demand that it is staked on its addressee's not being able reasonably to reject the principle that underlies it" (Darwall 2006, p. 301). Darwall provides a ground for contractualism in the sense that the contractualist principle characterizes legitimate second-personal claims. This ground is formal, in 
that it is structurally part of a certain way of engaging the world and independent from any particular commitments or values.

Darwall's formal foundation satisfies Strawson's point and overcomes his challenges to value-oriented foundations by identifying a significant aspect of the second-personal perspective. By grounding the authority of second-personal relationships in the (second-personal) way we relate to one another, he presents the right kind of considerations. Moreover, legitimate, mutually agreeable, second-personal demands have priority because of the close conceptual relationship between accountability and the right. Finally, since legitimate address emerges from a significant aspect of the second-personal way we relate to one another, Darwall's formal foundation affords moral relationships more than instrumental significance. The formal foundation overcomes the three challenges presented by Strawson's point.

\section{Second-personal values}

Strawson's point raises an objection to value-oriented foundations for contractualism by pointing to a category mistake. Third-personal reasons are different in kind from second-personal reasons. However, this category mistake only precludes all value-oriented foundations if all values are necessarily first or third personal. This is not the case. The criterion Darwall uses to distinguish second from third-personal demands further highlights an important difference in kinds of value. Applying Darwall's distinction to value, I show that many values only make sense from a second-personal perspective. Doing so identifies a class of second-personal values that could potentially serve as the foundation for contractualism without committing the category mistake.

The way Darwall distinguishes second from third-personal demands provides a standard for determining whether something is second personal. Stomper has two kinds of reasons to get off Irritated's foot: because it causes pain in the world and because she demands it. The latter demand cannot be understood from the third-personal, world-regarding perspective. Her

authority only makes sense within the perspective of the relationship. That is, the demand only makes sense when Irritated recognizes her as someone who can ask things of him. Importantly, this distinction between the second and third person primarily concerns the considerations relevant to two different perspectives for engaging others and the world. Are the concerns based on what I want (first personal), what is desirable (third personal), or are they internal to the relationship of mutual recognition you and I share (second personal). This marks the essential characteristic of second-personal claims: the content of the claim only make sense, or can only be fully explained, from the second-personal perspective. In order for Strawson's point to rule out value-oriented foundations, no value can require adopting this perspective. Instead, values must point to things that would be desirable (or valuable) to bring about in the world.

Fully recognizing or realizing many values requires adopting the second-personal perspective, and the content of these values cannot be fully understood from a world-regarding perspective. These values are second-personal values that require recognizing and responding to second-personal reasons for acting. The case of friendship helps to demonstrate the difference 
between second-personally valuing a friend and third-personally valuing the relationship of the friendship. Friendship serves as a nice case because it includes first-personal, second-personal and third-personal considerations. A full accounting for the value of friendship depends partly on prudential considerations (having friends increases the likelihood I can find people to help me move), partly on second-personal considerations (having someone who is willing to help you through a crisis because you're you) and partly on world-regarding considerations (friendships increase the amount of happiness in the world).

The third and first-personal ways of valuing friendship respond to third or first-personal considerations. Third personally, friendship is valuable, in part, because it makes people happy, helps people pursue and accomplish their projects and may help develop moral character. A world with friendship is better than one without, and these all provide some basis for wanting friendships in the world. Even if someone reject the third-personal value of friendship, he can value friendship first personally. Having friends makes me happy, helps me pursue my projects and may even help me develop my moral character. These all provide good prudential reasons to try to develop friendships. Moreover, these ways of valuing friendship can attach to aspects of the relationship like loyalty. A world with loyalty is better than one without, and it is better when people are loyal to me because that is something I want. While people usually value friendship for a variety of reasons, each of these captures a distinct way of valuing friendship. In principle, you can value friendship either first or third personally without valuing it the other way. Moreover, each provides a distinct basis for how to conceive of the value of helping your friends. Someone could go to watch a friend's show because a world in which people go to friends' shows is better, or I could go because doing so satisfies one of my desires.

These third and first-personal considerations cannot account for the second-personal value of friendship. Again, the difference goes back to Strawson's distinction between the objective perspective, viewing people as things in the world, and the participant reactive perspective, recognizing and engaging others as agents. Returning to how to conceive of the value of going to the show, from a second-personal perspective the value does not come from instantiating or realizing what makes the world go best. Instead, the value of going to the show comes from recognizing that your friend's interests provide you with a reason to act and affirming that recognition in your relationship. ${ }^{2}$ You should be loyal to friends, not because it makes the world go better, but because they are your friends. Someone can only be a friend in this way by recognizing second-personal reasons and the validity of second-personal forms of

\footnotetext{
2 Toni Rønnow-Rasmussen and Woldeck Rabinowicz (2000) defend the possibility of irreducible, final and non-intrinsic ends. While their discussion has a different focus, the project of this paper is very much in spirit of affirming the final value of a certain kind of relationship. For present purposes, three aspects of the discussion should be kept in mind. First, not all relational values are second-personal. Second, someone can do something for-the-sake-ofsomeone-else while treating them objectively, for example when caretaking. Third, the secondpersonal way of valuing a relation cannot be reduced to a first-personal or third-personal way of valuing even if the same relation can be valued first or third-personally. For more also see: Rønnow-Rasmussen, T (2002) and Rønnow-Rasmussen, T (2009).
} 
address. As the case of friendship brings out, some values are not only world regarding or selfregarding; they essentially include recognizing and responding to second-personal considerations. Importantly, the second-personal way of valuing friendship does not derive from the other ways friends may be valuable. Each mode of valuing is different in kind and so independently significant.

With this distinction in mind, Scanlon's discussion of the ideal of acting justifiably towards others illustrates how this ideal, like friendship, is irreducibly second personal. Unlike desirability, which does not invoke the participant perspective, acting justifiably towards others requires affirming and acting in accordance with appropriate second-personal relationships. We act justifiably towards others when we act in ways they cannot reasonably reject, and this reasonable rejection test centers around considering the strongest objections to these actions others can raise from their personal perspective. If Sally has significant objections to John performing an act and he does not have correspondingly significant reasons to perform the act, he should not do it. Since he has no response to her objections, performing the act would be unjustifiable. Valuing the ideal of acting justifiably towards others requires recognizing the need to justify yourself to others and that their personal objections to your actions have weight.

Like the case of friendship, these objections can have second and third-personal content. Sally could object to John's action on grounds that it will cause pain. The content of his objection is third personal - it concerns a state of affairs; however, recognizing that this value requires a response may be second personal. This is Sally's objection, and justifying an action to her requires responding to it. So, even when the objection being considered is third personal, the ideal of acting justifiably towards others presents an important second-personal reason to address it. Put differently, realizing the ideal does not require promoting some world-regarding end, it involves respecting others as standing in a certain relation to you. It is a second-personal value.

The ideal of acting justifiably towards others, as a second-personal value, meets Darwall's three challenges, thereby overcoming Strawson's point and potentially providing a foundation for contractualism. Establishing the ideal as an independent, second-personal value ensures that it potentially provides the right kind of ground for second-personal relationships and affords them more than derivative significance, overcoming Darwall's second and third objections. Moreover, the ideal of justifiability's relationship to other values establishes the priority of morality (Scanlon 1998, p. 166). To begin, the ideal responds to other values limiting how often it directly conflicts with these values. Values play an important initial role in determining what is justifiable. For contractualists, actions are wrong when they are prohibited by a principle that no one can reasonably reject. If a principle for action does not threaten anything of importance, it cannot be reasonably rejected. Hence, what people value partially determines what principles are justifiable by providing a basis for reasonable rejection. Since it responds to other values, the ideal of acting justifiably towards others will come into less conflict with those values. This lowers the bar for meeting the priority criterion since justifiability is sensitive to the important considerations people act on. 
In addition, the ideal will tend to be stronger than any other particular value when they do conflict because acting justifiably towards others serves as a precondition for or partly constitutes a wide range of important values, particularly those concerning personal relationships and collective pursuits (Scanlon 1998, p. 164). The value of everything from earning a degree to sports requires everyone engage in the enterprise of acting justifiably towards others. For example, the significance of my degree and the accomplishment in earning it require certain academic standards to be in place. The value of the degree is undermined when no one ever fails or everyone cheats. The value in earning a degree requires both students and teachers act fairly, in accordance with reasonable academic standards. Good students earn their degrees in the right way, in a way that is justifiable. We have reason to act justifiably (and to prioritize acting that way) because doing so allows us to realize these values that depend on mutual recognition. The way the ideal of acting justifiably towards others relates to a myriad of values, particularly those involving interpersonal pursuits, gives us strong reasons to prioritize considerations of justifiability in our practical thinking. Taken together, the value of acting justifiably towards others will tend to have priority over other values because it limits instances of conflict and has a central place in many people's system of values.

Even if the ideal of acting justifiably towards others satisfies Strawson's point by establishing the priority or moral considerations and serving as a potential ground for secondpersonal reasons, Darwall argues that the value cannot provide the basis for appropriate authority relationships. In reply to critics, he states, "my point is simply that as significant as this value [of engaging with others justifiably] is to us, it gives us reasons of the wrong kind to think that we actually are answerable to one another" (Darwall 2007, p. 69). Darwall's right. The wide-ranging significance of the value of acting justifiably establishes only its priority. The second-personal content of the ideal of justifiability is what potentially grounds second-personal authority relations. That is, the significance of the value explains why you should act justifiably. What it means to act justifiably is to act in accordance with principles that no one reasonably rejects and presumably to sanction actions that violate such principles. The ideal of acting justifiably towards others - as a value and not a formal aspect of reasoning - overcomes the challenges based on Strawson's point. It is a candidate for the foundation of contractualism. In the next section, I suggest several reasons the ideal serves as a better foundation than Darwall's formal second-personal perspective.

\section{Comparing the Formal and Value-oriented foundations}

Both formal and value-oriented approaches to contractualism can affirm that mutual justifiability describes the appropriate way to mediate personal relations. Each approach, however, provides a different basis for the priority of morality. Darwall's formal approach ensures the priority of moral considerations by treating justifiability as a prerequisite for legitimate second-personal address. As seen in the previous section, a value-oriented approach establishes the priority of morality only if people value the myriad of pursuits or values that involve mutual recognition. This central difference between the two approaches has implications 
about the nature of other contractualist values, especially the key notions that actions should be justifiable to each and that normative principles should express equality. Where the formal foundation only ensures equality at the level of norm acceptance, the value-oriented foundation further ensures a degree of relative equality in the content of the norm. This difference follows from how the respective foundations explain the way moral principles are justified to each person. The formal foundation justifies principles to each qua second-personal agent. In contrast, the value-oriented foundation justifies principles to different standpoints better representing the differences among persons. Simply put, grounding contractualism in a formal aspect of secondpersonal reasoning captures much weaker versions of these contractualist ideals than a commitment to the ideal of justifiability

Darwall's example of the sergeant illustrates the kind of equality established by the formal foundation. When the sergeant orders the private to do push-ups and the private accepts the demand, each treats the other as someone who can recognize and accept the authority relationship. Darwall appeals to this shared recognition to argue for a kind of equality. Analyzing second-personal demands, Darwall states, "addressing second-personal reasons always presupposes not just the addresser's authority and competence to hold the addressee responsible for compliance, but also the addressee's authority and competence to hold himself responsible" (Darwall 2006, p. 138). Second-personal competence involves the ability to recognize, issue and hold yourself and others accountable for legitimate demands. ${ }^{3}$ So, by issuing a second-personal demand to you, I assume you are second-personally competent and thus can recognize my authority from our shared perspective. However, the same competence that enables you to hold yourself accountable to my demands enables you to make demands on me (which I recognize since I must be second-personally competent to issue a demand). Again, your demands of me will be legitimate only if each person could agree to them from our shared perspective. All legitimate demands require the individuals acknowledge and treat one another as equal members of the morality community due to second-personal competence.

This equality of second-personal competence, however, is consistent with very unequal relationships. Relationships depend on the relative position each person occupies. Darwall contends that while "the sergeant, of course, addresses her order to not just any rational person but to the private, there is an important sense in which her addressee must be conceived to be aperson-who-happens-to-be-a-private" (Darwall 2006, p. 260). Herein lies the problem. The formal equality Darwall defends is only an equal ability to affirm a formal authority relationship between someone-who-happens-to-hold-this-position and someone-who-happens-to-hold-thatposition. As evidenced when Darwall explains how the second-personal perspective can accommodate the unequal power relationships of slavery (Darwall 2006, p. 267) and our subordination to God (Darwall 2006, p. 108) as potentially legitimate authority relationships, his second-personal perspective places no substantive constraint on acceptable authority

\footnotetext{
${ }^{3}$ Gary Watson (2007, p. 42) puts pressure on Darwall's claim that having the capacity to issue a
} demand entails the ability to hold responsible. 
relationships. ${ }^{4}$ Rather, Darwall acknowledges that for a slave owner to successfully issue a second-personal demand, he must presuppose that the slave can affirm the authority relationship and recognize she happens to be in the position of the slave. ${ }^{5}$ While Darwall affirms equality at the level of accepting authority relations, this equality does not place limits on what the accepted authority relationship may be.

This formal notion of equality follows, in part, from the point of view relevant to justification - the second-personal perspective. Since agency requires being able to share this moral perspective, justifying a principle or relationship to the second-personal perspective justifies it to each agent. While essentially recognizing others' agency, this glosses over the differences among people. Individuals or groups with different aims who find themselves in different circumstances each receive the same justification. So, Darwall's formal account captures a notion of justification to each qua second-personal agent, and the justification always targets one perspective.

In contrast, using the ideal of justifiability as a foundation justifies principles to different standpoints. Importantly, like Darwall's formal foundation, the ideal of justifiability is second personal; the content of the value only makes sense from the second-personal perspective. As such, the ideal provides a way to ground second-personal relationships without committing the category mistake at the heart of Strawson's point. As a value, however, the ideal has more content to draw upon to place substantive restrictions on the rules and relationships it grounds. Importantly, sharing the aim of finding reasonable principles does not require everyone adopt the same standpoint. Scanlon puts the point this way, "in the contractualist analysis of right and wrong, what is presupposed first and foremost is the aim of finding principles that others who share this aim could not reasonably reject. This aim brings other reasons in its train" (Scanlon 1998, p. 192). These other reasons are those that come from a commitment to recognizing and engaging others as agents with standing to reject certain principles for action. Treating them reasonably requires taking their concerns and considerations into account. As noted in the previous section, the ideal of justifiability is related to a myriad of other values involving mutual recognition. Since we recognize others as having different values and pursuits, assessing whether a principle is reasonably rejectable involves weighing the objections that can be raised against adopting or rejecting a principle from different standpoints (Scanlon 1998, pp. 195, 202-206). Each standpoint represents someone's "situation, characterized in general terms, and [includes] such things as their aims and capabilities and conditions in which they are placed" (Scanlon 1998, p. 204). Darwall's second-personal perspective streamlines this information. While the information may be part of deliberation within the second-personal perspective, the standpoints do not represent unique perspectives to which justification is due. By addressing justification to

\footnotetext{
4 This is similar to Watson's point that Darwall's move from morality as mutual accountability to morality as equal accountability adds substantive constraints.

${ }^{5}$ Darwall is obviously against slavery. However, he takes this position to be a substantive claim that does not follow from his formal analysis.
} 
different standpoints rather than a shared perspective, this value-oriented approach takes the differences among persons more seriously.

Distinguishing standpoints is important, at least in part, because it ensures considerations of equality play a role at two levels. First, like Darwall's formal account, building on the ideal of justifiability requires that all moral principles be reasonably acceptable (or stronger, not reasonably rejectable) from each standpoint. This ensures equality plays a role in the justification of principles or authority relations since each person is able to affirm them. Unlike the formal account, however, the reasonable acceptance does not invoke a single standpoint. Instead, each person reasonably accepts principles from her standpoint recognizing the legitimacy of others' standpoints. Second, grounding contractualism in a shared value, like the ideal of justifiability, rather than a shared capacity for second-personal address allows a value-oriented foundation to secure a greater degree of equity in the content of the principles or relations that it justifies. Basing equality on second-personal capacity alone in principle permits the excessive imbalance in the content of the relationships between masters and slaves, people and gods or within a caste system. Since the ideal of justifiability recognizes the considerations of people from their different standpoints as significant, the ideal places substantive restrictions on the content of justified relationships. The considerations from difference standpoints serve as potential bases of reasonably rejecting a principle, acting as potential vetoes. These restrictions will not require absolute equality since some imbalanced relationships, like those between teachers and students, are acceptable from both standpoints. However, the restrictions limit the degree of imbalance since whatever standpoint becomes most burdened becomes the site of justification. Treating people in that standpoint reasonably requires recognizing and responding to the objections that can be raised from that standpoint, which will rule out cases like slavery as potentially legitimate authority relations. They will have very strong objections.

Darwall's insight about the second-personal perspective marks an important advancement for moral theory generally and contractualism in particular. The second-personal perspective captures an essential aspect of our moral relationships, and I have argued that it further captures a unique set of values. I appreciate Darwall's attempt to locate an irreducibly second-personal ground for reasons that provides a firmer, more general foundation for contractualism. Despite these advantages, relying on a second-personal value, like the ideal of justifiability, comes at a much lower cost. Basing contractualism on the ideal of justifiability secures more familiar versions of the contractualist ideals that moral principles should be justifiable to each while expressing equality in both the justification and content of the principles.

\section{Acknowledgements}

I extend special thanks to the members of Penn's moral philosophy reading group, especially Adrienne Martin, Jeppe von Platz and Chris Melenovsky, for their helpful comments and to Stephen Darwall for a stimulating evening of conversation. I would further like to thank those 
who attended the presentation of an earlier version of the paper at the 2010 Central Division Meeting of the American Philosophical Association, including Daniel Groll for his comments.

\section{References}

Darwall S (2006) The second-person standpoint. Harvard University Press, Cambridge.

Darwall S (2007) Reply to Korsgaard, Wallace and Watson. Ethics 118:52-69.

Freeman S (1991) Contractualism, moral motivation, and practical reason. J of Philos 88:281303.

Rabinowicz W, Ronnow-Rasmussen T (2000) A distinction in value: intrinsic and for its own sake. Proc. of the Aristot Society 100:33-51.

Rønnow-Rasmussen T (2002) Instrumental values: strong and weak. Ethical Theory and Moral Prac 5:23-43.

Rønnow-Rasmussen T (2009) On for someone's sake attitudes. Ethical Theory and Moral Prac 12:397-411.

Scanlon TM (1998) What we owe to each other. Harvard University Press, Cambridge.

Scanlon TM (1982) Contractualism and utilitarianism. In: Sen A, Williams B (eds) Utilitarianism and beyond. Cambridge University Press, Cambridge, pp 103-128.

Strawson PF (1962) Freedom and resentment. Proc of the Br Acad 48:1-25.

Watson G (Oct. 2007) Morality as equal accountability: comments on Stephen Darwall's the second-person standpoint. Ethics 118:37-51. 